\title{
Alcohol and other substance abuse among youth: an obvious but neglected scenario in Shimla city of Himachal Pradesh, India
}

Sir,

Shimla, the former summer capital of the British in India, and the present capital of Himachal Pradesh, is the principal commercial, political and educational centre of the hilly regions of the state. For all these values, more than $1,60,000$ people from different region of state are residing in urban area of Shimla. ${ }^{1}$ Moreover, thanks to its picturesque natural locales and pleasant climate it also attracts thousands of tourists every day. With due regards to all its importance, we want to highlight one rapidly growing social and public health problem in the city i.e. substance abuse. Substance abuse particularly among youth has become quite evident in the city in the form of alcohol, cigarette and other tobacco products, cannabinoid and opium extracts. Many contributing factors responsible for current scenario, which are being overlooked again and again, are described here as following.

Substance abuse in various forms has always been culturally and socially acceptable particularly among adult in this hilly state of northern India. Angoori (a local grape wine from Kinnaur region), moori (local apple wine from upper region of Shimla Kullu Kinnaur), Aara (famous local drink from Lahual and spiti), Chhang and lugdi are some of the different forms of alcohol beverages that are freely brewed, distributed and consumed at home without any restriction. Tobacco use in different forms (bidi, hukkah, chilam) has been used for ages by the people of Himachal. Cannabinoid extracts (Malana cream, Charas, bhang) from Kullu district and upper region of state is worldwide known and are one of the main reason for many of the tourists to visit this state. Opium extracts (afeem) from poppy plant has been used for minor ailment as well as for recreational use in most part of the state. If we see historically the patterns of substance use has evolved constantly, and from ceremonial or occasional use, it has become a regular part of life style (particularly alcohol and tobacco products). People from different parts of state have carried their behavior along with them to the capital city and young generation being more experimental and having more freedom has taken it to the next level. So our strong past legacy has definitely attributed for current rise in substance abuse among youth.

Again with the impact of globalization, urbanization, industrialization, media influence and changing lifestyle, these evils has entered into the lives of youth in a big and unrestricted manner. Most of young population in Shimla are either studying in school, colleges or university or has just started their career in various fields. Most of them are living separately from their families and don't have many of the restriction which normally a traditional pahari family used to have on their children. Even those who are living with family have enough time to experiment with these drugs considering different factors like busy schedules of parents, lack of parental care or even if parents are themselves using one or more forms of these drugs.

Tourism, which is considered as an important source of revenue for state has also flared the problem of substance abuse in the city among youth. Tourist destinations have always been the interest area of different drug rackets and mafias. Whereas alcohol and tobacco products are freely available for everyone, other substances are not that hard to find out through their agents. Majority of tourists visit hill station just for the sake of fun and enjoyment. You can notice many people drinking, dancing and smoking right on road-side in and around Shimla, on the ridge and the mall road, most secured and visited place in Shimla city. They get carried away on the name of enjoyment and tourism but the impact it has on our children and youth can't be ignored. Hardly any actions are being taken against them which give a wrong message to our young generation for whom enjoyment has become synonymous with loud music, pubs/bar and drugs.

Legislative efforts to control substance abuse don't look very promising either, as we can see people smoking publically, wine shops selling alcohol to minors, smokeless tobacco products being sold even after ban. Most of the bars in Shimla city allow minors to drink and smoke keeping their monetary benefits above the law. Control over drug rackets and mafias seem largely inadequate though sometime we do read few headlines regarding drugs in the newspaper. ${ }^{2-4}$

Current lifestyle, high levels of stress and anxiety, low self-esteem, depressive symptoms, susceptibility to peer pressure and problems associated with education or career has become ideal catalyst for youth to get trapped in the illusionistic world of drugs. Though not much scientific data on this problem is available still some studies has reported high level of alcohol and tobacco use among adolescent and youth in Shimla City. ${ }^{5-7} \mathrm{We}$ need to understand the depth of this problem rather than neglecting it before the situation go out of hand like our 
neighboring states of Punjab/Haryana/Chandigarh where huge number of Youth are being reported as drug addict. ${ }^{8-10}$ We recommend to study current scenario of substance abuse in Shimla city and to develop a comprehensive program to combat the problem.

\section{Devender Kumar*, Anupam Parashar, Anita Thakur}

Department of Community Medicine, Indira Gandhi Medical College, Shimla, Himachal Pradesh, India

*Correspondence to:

Dr. Devender Kumar

E-mail: dev10121986@gmail.com

\section{REFERENCES}

1. Municipal Corporation Shimla. Shimla Municipal Corporation at a Glance. Available at: http://www.shimlamc.gov.in/page/GeneralProfile.as px. Accessed on 03/06/2016.

2. Himachal watcher. Shimla Police tightens grip on drug peddlers, dealers, suppliers. February 4, 2016. Available at: https://himachalwatcher.com/2016/02/04/shimlapolice-tightens-grip-on-drug-peddlers-dealerssuppliers/. Accessed on 04/06/2016.

3. The times of India. Courier firm owner held in drug racket. Apr 3, 2016. Available with http://timesofindia.indiatimes.com/city/delhi/Courie r-firm-owner-held-in-drug racket/articleshow/51665698.cms. Accessed on 04/06/2016.

4. Shimla times in Drug racket: ED attaches property of six accused. December 21, 2015. Available at: http://www.shimlatimes.in/2015/12/drug-racket-edattaches-property-of.html. Accessed on 04/06/2016.

5. Sharma P, Thakur A. Pattern of substance abuse in patients attending psychiatry OPD of IGMC, Shimla. IOSR Journal of Dental and Medical Sciences. 2014;13(8):853-61.

6. Kumar D, Parashar A, Thakur A. Tobacco Use and its Correlates among Youth in a Northern Urban City of India. Int Jour Science Research. 2016;5(3):1577-82.

7. Thakur D, Gupta A, Thakur A, Mazta SR, Sharma D. Prevalence of cigarette smoking and its predictors among school going adolescents of North India. South Asian J Cancer. 2014;3(4):193-5.

8. Punjab drug epidemic. Drug abuse statistics for punjab. Available at: http://alcoholrehab.com/drugaddiction/punjab-drug-epidemic/. Accessed on 03/06/2016.

9. Mahajan S. Drug use rising among adolescents in Chandigarh. The Indian express. Chandigarh. Available at: http://indianexpress.com/article/cities/chandigarh/dr ug-dealers-punjab-drug-use-rising-amongadolescents-in-chandigarh/. Accessed on 02/06/2016.

10. Times of India. Haryana not far behind Punjab in drug addiction: Experts. Mar 30, 2015 Available at: http://timesofindia.indiatimes.com/india/Haryananot-far-behind-Punjab-in-drug-addictionExperts/articleshow/46740424.cms. Accessed on 01/06/2016.

Cite this article as: Kumar D, Parashar A, Thakur A. Alcohol and other substance abuse among youth: an obvious but neglected scenario in Shimla city of Himachal Pradesh, India? Int J Community Med Public Health 2016;3:2355-6. 